\title{
Low vitamin $D$ in dark-skinned immigrants is mainly due to clothing habits and low UVR exposure: a Danish observational study
}

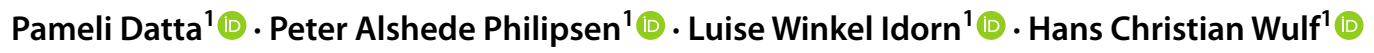

Received: 1 May 2021 / Accepted: 11 October 2021 / Published online: 31 October 2021

(c) The Author(s), under exclusive licence to European Photochemistry Association, European Society for Photobiology 2021

\begin{abstract}
Low 25-hydroxyvitamin $\mathrm{D}_{3}(25(\mathrm{OH}) \mathrm{D})$ among dark-pigmented persons has been observed. To elucidate the reason for this we examined sun behaviour, sun-exposed body area, solar UVR exposure and 25(OH)D levels in immigrants with dark pigmented skin and Danes with light pigmented skin. Clothing, sun behaviour, and diet were recorded daily during a Danish summer season (93 analysed days). Erythema-weighted UVR doses were measured by personal electronic UVR dosimeters (with erythema response, measurement every 5th second) and 25(OH)D was measured in 72 participants (33 dark-skinned and 39 light-skinned). The immigrants exposed $28 \%$ less skin area, received $70 \%$ less UVR dose, and had $71 \%$ less $25(\mathrm{OH})$ D increase during the summer. The UVR reactivity $(\Delta 25(\mathrm{OH}) \mathrm{D}$ per joule accumulated UVR dose) was similar $(P=0.62)$ among the immigrants $\left(0.53 \mathrm{nmol}^{-1} \mathrm{~J}^{-1}\right)$ and the Danes $\left(0.63 \mathrm{nmol}^{-1} \mathrm{~J}^{-1}\right)$. In the groups combined, 25(OH)D levels after summer were mainly influenced by UVR dose to exposed skin $(28.8 \%)$ and $25(\mathrm{OH}) \mathrm{D}$ start level $(27.9 \%)$. Height and measured constitutive skin pigmentation were of minor influence: $3.5 \%$ and $3.2 \%$, respectively. Sun exposure and clothing habits were the main reasons for lower $25(\mathrm{OH}) \mathrm{D}$ level after summer in the darker immigrants, as both groups had similar UVR reactivity.
\end{abstract}

\section{Graphical abstract}

UVR, sun exposed BSA, $25(\mathrm{OH}) \mathrm{D}_{3}$ increase and UVR reactivity

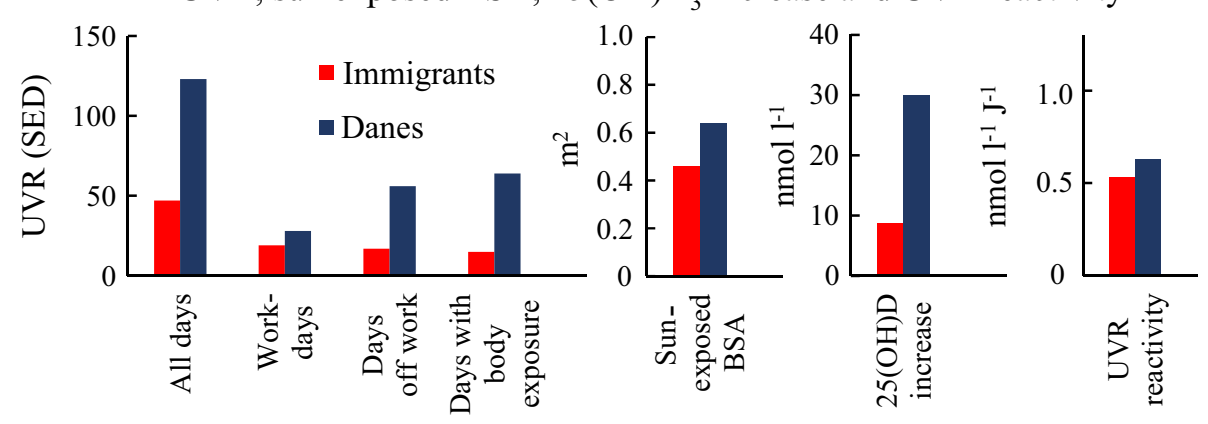

\section{Introduction}

When human skin is exposed to UVR from terrestrial sunlight, cutaneous 7-dehydrocholesterol (7-DHC) is converted into previtamin $\mathrm{D}_{3}$ ultimately leading to the formation of the bioactive vitamin $\mathrm{D}, 1,25(\mathrm{OH}) 2 \mathrm{D} 3$ [1]. Melanin (pigment)

Pameli Datta

pameli@outlook.dk

1 Department of Dermatology D92, Bispebjerg Hospital, University of Copenhagen, Nielsine Nielsens Vej 17, 2400 Copenhagen NV, Denmark in skin absorbs UVR [2-4] and can offer more than 20-fold protection against skin cancer [5-7]. The melanin protection factor is $8-10$ for erythema and around 60 for DNA photodamage in the basal layer of the skin [6].

Individuals with relatively darkly pigmented skin display insufficient $\left(<50 \mathrm{nmol} \mathrm{l}^{-1}\right)$ serum 25 -hydroxyvitamin $\mathrm{D}_{3}$ $(25(\mathrm{OH}) \mathrm{D})$ levels much more frequently than individuals with more lightly pigmented skin. This is particularly common when persons with dark skin immigrate to higher latitudes with less ambient UVB, but is generally present irrespective of their place of residence [8]. This phenomenon is 
often ascribed to the absorption of solar ultraviolet radiation (UVR) by melanin in skin [4], hereby lowering the formation of vitamin D [9-11].

Nevertheless, studies investigating the influence of skin pigmentation on UVR-induced vitamin D production have yielded conflicting results [12-15]. In a short-term study (10 days) with artificial UVR no influence of pigmentation was found [12]. In a similar long-term study ( 9 weeks) there was an influence of measured skin pigmentation, but this influence may be due to genetic factors. This suggests that skin pigmentation may not constitute a genuine influence [14]. Even if there is an inhibitory effect of skin pigmentation, these controlled UVR studies show that this may be minimal [15].

Recently, Young et al. exposed groups consisting of 5-19 volunteers representing Fitzpatrick skin types II, III, IV, V and VI to a series of 5 artificial and sub-erythemal UVR irradiations of $85 \%$ of their BSA over 2 weeks. Significant difference in the slopes of $25(\mathrm{OH}) \mathrm{D}$ increase was detected only between the most extreme phenotypes Fitzpatrick skin type VI and II, corresponding to a photo inhibition factor of melanin of around 1.3. This was much less than the photoprotection offered for erythema and DNA photodamage, but enough to explain a difference in $25(\mathrm{OH}) \mathrm{D}$ status of $27 \mathrm{nmol}^{-1}$ observed between whites and blacks [16]. Still, in volunteers with Fitzpatrick skin type II-V there were no differences in the slopes of UVR-induced 25(OH)D increase. Therefore, the low vitamin D status found in persons from areas, such as Asia, The Middle East and North Africa with intermediately pigmented skin cannot be explained by skin pigmentation.

We, therefore, proceeded to illuminate other parameters that may influence vitamin $\mathrm{D}$ level by investigating the real-life differences in sun behaviour, clothing/sun-exposed body surface area (BSA), solar UVR exposure and 25(OH) $\mathrm{D}$ increase between a group of participants of non-Danish origin with dark-pigmented skin ('immigrants') and a group of participants with Danish origin with light-pigmented skin ('Danes'). All participants were residents of Denmark. As they went about their everyday lives, participants in the study wore individual UVR dosimeters and filled in a diary containing questions regarding sun behaviour, clothing (i.e., sun-exposed BSA) and diet during late spring and summer in Denmark.

\section{Results}

\subsection{Participants and their demographic characteristics}

Demographic data are shown in Table 1. Seventy-two participants residing in the capital region on Zealand (an area of $2563 \mathrm{~km}^{2}$ ) were included in the analysis. Thirty-three participants were 'immigrants` (non-Danish origin, Fitzpatrick skin types IV-VI) and 39 were 'Danes' (Danish origin, Fitzpatrick skin types I-IV). Skin pigmentation was measured as pigment protection factor (PPF). The immigrants (Group I) had dark skin with a mean constitutive PPF of 10 and mean facultative PPF of 11. The Danes (Group D) had lighter pigmented skin with a mean constitutive PPF of $4.3\left(P=3.4 \times 10^{-15}\right)$ and a mean facultative PPF of 6.7 $\left(P=1.9 \times 10^{-13}\right)$. A mean of facultative PPF measured at study start and study end was used to consider the increase in this parameter during summer. There were no group differences in sex distribution, age and BSA $(P \geq 0.76)$. Group I were shorter $(P=0.010)$ and had a higher body mass index (BMI, $P=0.0032$ ). Most of the participants were indoor workers $(85 \%)$ with no significant group difference $(P=0.32)$.

\subsection{Diary data}

The diaries provided information about behaviour in the sun, clothing and diet (Table 2). Sun behaviour parameters were number of days spent (1) at work, (2) off work, (3) on holiday, (4) abroad, (5) with body exposure, i.e., exposing shoulders, upper body and/or sunbathing, with sunburn and (6) using sunscreen as daily recorded in a questionnaire. Furthermore, sun behaviour parameters were also daily and accumulated UVR received on days (7) at work, (8) off work, (9) on holiday, (10) abroad and (11) with body exposure.

The mean number of study days between the two $25(\mathrm{OH})$ D measurements performed was $120(\mathrm{SD}=14$, range 84-143) for the groups combined. There were no significant group differences in the number of days analysed, i.e., days with both diary and UVR data available (mean: 93 days, $\mathrm{SD}=19$, range 30-129, $P=0.21$ ), workdays, days off work, holidays and days spent abroad (Table 2). Thus, the basic parameters, were comparable for the two groups. Despite this, the DS had half as many days with sunburn and with body exposure (Table 2).

Group I used sunscreen on 13 days, Group D on 15 days $\left(P=8.2 \times 10^{-3}\right)$. The mean sun protection factor $(\mathrm{SPF})$ was 27 (SD = 13, range: 13-50) for the Group I and 21 for Group $\mathrm{D}(\mathrm{SD}=13$, range: $13-50, P=0.35)$. The intake of fatty fish meals was also recorded daily in the diary and was lower in Group I $(P=0.019$, Table 1$)$.

\subsection{UVR dosimeter data and sun-exposed BSA}

The personal electronic UVR dosimeters measured erythema-weighted UVR doses every 5 th second and an average of the measurements was registered every 5 min. (timestamped doses) [17-19]. All data are shown in Table 3. 
Table 1 Demographic characteristics
Table 2 Number of days performing the listed activities

\begin{tabular}{|c|c|c|c|}
\hline Parameters & Immigrants $^{\mathrm{a}}$ & Danes $^{\mathrm{a}}$ & $P$ value ${ }^{\mathrm{b}}$ \\
\hline Participants-no & 33 & 39 & \\
\hline Sex-no. female/male & $19 / 14$ & $23 / 16$ & 1.00 \\
\hline Age-years & $40 \pm 11(22-70)$ & $42 \pm 14(22-73)$ & 0.93 \\
\hline Weight—kg & $75 \pm 15(51-103)$ & $75 \pm 17(53-123)$ & 0.667 \\
\hline Height $-\mathrm{cm}$ & $168 \pm 11(153-190)$ & $175 \pm 8.3(163-200)$ & 0.010 \\
\hline $\mathrm{BMI}-\mathrm{kg} / \mathrm{m}^{-2}$ & $26 \pm 3.6(22-38)$ & $24 \pm 4.6(17-42)$ & 0.0032 \\
\hline $\mathrm{BSA}-\mathrm{m}^{2}$ & $1.9 \pm 0.2(1.5-2.3)$ & $1.9 \pm 0.2(1.6-2.5)$ & 0.76 \\
\hline Constitutive $\mathrm{PPF}^{\mathrm{c}}$ & $10 \pm 4.9(4.2-21)$ & $4.3 \pm 0.8(2.9-6)$ & $3.4 \times 10^{-15}$ \\
\hline Mean facultative PPF during study & $11 \pm 3.1(7.1-19)$ & $6.7 \pm 1.2(3.9-9.6)$ & $1.9 \times 10^{-13}$ \\
\hline Fitzpatrick skin type—nos. I/II/III/IV/V/VI & $0 / 0 / 0 / 2 / 24 / 7$ & $8 / 18 / 9 / 4 / 0 / 0$ & $3.8 \times 10^{-19}$ \\
\hline Fatty fish meals per day ${ }^{\mathrm{d}}$ & $0.31 \pm 0.29(0-1.4)$ & $0.39 \pm 0.24(0-1.1)$ & 0.019 \\
\hline $\begin{array}{l}\text { Work status-Indoor worker/Partial outdoor } \\
\text { worker/Retired or unemployed }\end{array}$ & $29 / 0 / 4$ & $32 / 3 / 4$ & 0.33 \\
\hline 25(OH)D start level—nmol $1^{-1}$ & $47 \pm 25(12-107)$ & $55 \pm 23(23-106)$ & 0.12 \\
\hline
\end{tabular}

Values were given in numbers or mean $\pm \mathrm{SD}$ (range)

$P P F$ skin pigment protection factor, $B S A$ body surface area, $B M I$ body mass index

${ }^{a}$ Immigrants originated from countries south of latitude $45^{\circ} \mathrm{N}$ and had dark pigmented skin. Danes had primarily Danish ancestry with the exception of three parents being from Sweden, The Faroe Islands and Northern Germany. They had relatively light pigmented skin

${ }^{\text {b}}$ Statistical differences between the two groups were tested with Fisher's test, Pearson's $\mathrm{Chi}^{2}$ or MannWhitney $U$ test (all two-sided tests). Boldface indicates statistical significance at $P<0.05$

${ }^{c} \mathrm{PPF}$ is an objective measurement of skin phototype with a measurement range of $1-25$. Constitutive PPF was measured on buttocks. Facultative PPF was measured on the back of shoulders in the study period

${ }^{\mathrm{d}}$ The maximal number of fatty fish meals per day was 2

\begin{tabular}{|c|c|c|c|}
\hline Activity & Immigrants $^{\mathrm{a}}$ & Danes $^{a}$ & $P$-value ${ }^{\mathrm{b}}$ \\
\hline Study period ${ }^{c}$ & $124 \pm 14(84-140)$ & $116 \pm 13(95-143)$ & 0.0052 \\
\hline Days analysed ${ }^{\mathrm{d}}$ & $89 \pm 22(30-129)$ & $95 \pm 16(60-124)$ & 0.21 \\
\hline At work & $45 \pm 22(0-75)$ & $42 \pm 20(0-73)$ & 0.29 \\
\hline Off work (e.g., weekend) & $30 \pm 24(0-100)$ & $40 \pm 26(12-116)$ & 0.076 \\
\hline On holiday (i.e., vacation) & $13 \pm 16(0-66)$ & $14 \pm 12(0-48)$ & 0.54 \\
\hline Abroad (i.e., outside Denmark) & $7.8 \pm 12(0-44)$ & $5.5 \pm 10(0-53)$ & 0.82 \\
\hline With body exposure ${ }^{e}$ & $9.8 \pm 14(0-58)$ & $20 \pm 16(0-67)$ & $1.2 \times 10^{-3}$ \\
\hline On the beach & $3.7 \pm 5.5(0-23)$ & $10 \pm 17(0-96)$ & $8.4 \times 10^{-3}$ \\
\hline Sunburned (red from the sun) & $0.3 \pm 0.8(0-4)$ & $2.3 \pm 2.4(0-10)$ & $1.0 \times 10^{-9}$ \\
\hline Using sunscreen & $13 \pm 29(0-113)$ & $15 \pm 18(0-75)$ & $8.2 \times 10^{-3}$ \\
\hline
\end{tabular}

Values were given as number of days in mean \pm SD (range)

$U V R$ ultraviolet radiation

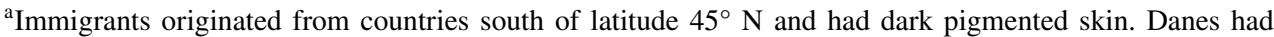
primarily Danish ancestry with the exception of three parents being from Sweden, The Faroe Islands and Northern Germany. They had relatively light pigmented skin

${ }^{\mathrm{b}}$ Statistical differences between the two groups were tested with Mann-Whitney $U$ test (two-sided test). Boldface indicates statistical significance at $P<0.05$

${ }^{\mathrm{c}}$ The study period was the time between the first and the last 25(OH)D blood sample. Mean study start date for the Immigrants was 5th May \pm 12 (1st May-22nd June) and 9th May \pm 12 (19th April-1st June) for the Danes. Mean study end date was 4th September \pm 8.3 (31st July-17th September) for the Immigrants and 1 st September \pm 12 (22nd August-21st September) for the Danes

${ }^{\mathrm{d}}$ During study period, only days with available UVR and diary data were analysed further

${ }^{\mathrm{e}}$ Body exposure was defined as exposing shoulders, upper body and/or sunbathing 
Table 3 UVR dose, sun-exposed BSA and 25(OH)D

\begin{tabular}{|c|c|c|c|c|}
\hline & Immigrants $^{\mathrm{a}}$ & Danes $^{\mathrm{a}}$ & Difference $(\%)^{\mathrm{b}}$ & $P^{`}$ value \\
\hline \multicolumn{5}{|l|}{ UVR per day (SED) } \\
\hline Days analysed $^{\mathrm{d}}$ & $0.5 \pm 0.4(0.1-1.9)$ & $1.3 \pm 0.8(0.2-4.1)$ & $0.8(62)$ & $1.3 \times 10^{-8}$ \\
\hline Workdays & $0.4 \pm 0.4(0.1-1.9)$ & $0.6 \pm 0.4(0-2.1)$ & $0.2(33)$ & $5.9 \times 10^{-3}$ \\
\hline Days off work (e.g., weekend) & $0.5 \pm 0.4(0-1.9)$ & $1.5 \pm 0.8(0.4-4.2)$ & $1.0(67)$ & $1.8 \times 10^{-10}$ \\
\hline Holidays (i.e., vacation) & $1.1 \pm 1.8(0-7.4)$ & $3.5 \pm 4.5(0.1-24)$ & $2.4(69)$ & $9.3 \times 10^{-5}$ \\
\hline Days abroad (i.e., outside Denmark) & $1.1 \pm 1.8(0-6.7)$ & $4.3 \pm 4.8(0-15)$ & $3.2(74)$ & 0.011 \\
\hline Days with body exposure ${ }^{\mathrm{e}}$ & $0.5 \pm 0.4(0.1-1.9)$ & $0.8 \pm 0.4(0.2-1.8)$ & $0.3(37)$ & $2.4 \times 10^{-5}$ \\
\hline \multicolumn{5}{|l|}{ Accumulated UVR (SED) } \\
\hline Days analysed $^{\mathrm{d}}$ & $47 \pm 41(7.6-166)$ & $123 \pm 61(22-267)$ & $76(62)$ & $1.4 \times 10^{-8}$ \\
\hline Workdays & $19 \pm 22(0.9-121)$ & $28 \pm 19(0-87)$ & $9(32)$ & $3.6 \times 10^{-3}$ \\
\hline Days off work & $17 \pm 19(0.6-79)$ & $56 \pm 41(8.8-178)$ & $39(70)$ & $3.1 \times 10^{-8}$ \\
\hline Holidays & $19 \pm 25(0-98)$ & $54 \pm 45(0.3-159)$ & $35(65)$ & $1.0 \times 10^{-3}$ \\
\hline $\begin{array}{l}\text { Days with body } \\
\text { exposure }^{\mathrm{e}}\end{array}$ & $15 \pm 18(0.2-79)$ & $64 \pm 60(1.4-230)$ & $49(77)$ & $4.7 \times 10^{-5}$ \\
\hline \multicolumn{5}{|l|}{ Sun-exposed BSA ${ }^{f}$} \\
\hline In $\mathrm{m}^{2}$ & $0.46 \pm 0.2(0.1-0.9)$ & $0.64 \pm 0.2(0.3-1.1)$ & $0.18(28)$ & $6.5 \times 10^{-4}$ \\
\hline $\begin{array}{l}\text { Accumulated } \\
\text { UVR to the skin }(J)^{\mathrm{f}}\end{array}$ & $25 \pm 31(1.4-137)$ & $82 \pm 60(11-280)$ & $57(70)$ & $1.8 \times 10^{-9}$ \\
\hline \multicolumn{5}{|l|}{$25(\mathrm{OH}) \mathrm{D}\left(\mathrm{nmol} 1^{-1}\right)$} \\
\hline Start level & $47 \pm 25(12-107)$ & $55 \pm 23(23-106)$ & $8(14)$ & 0.12 \\
\hline End level & $55 \pm 24(12-103)$ & $85 \pm 24(31-132)$ & $30(35)$ & $5.4 \times 10^{-6}$ \\
\hline Increase & $8.7 \pm 20(-48-49)$ & $30 \pm 22(-7.3-76)$ & $21(71)$ & $1.5 \times 10^{-4}$ \\
\hline Daily increase & $0.1 \pm 0.2(-0.4-0.4)$ & $0.3 \pm 0.2(-0.1-0.8)$ & $0.2(67)$ & $3.5 \times 10^{-5}$ \\
\hline
\end{tabular}

Values were given in mean \pm SD (range)

$U V R$ ultraviolet radiation, $B S A$ body surface area, $S E D$ standard erythema dose

${ }^{a}$ Immigrants originated from countries south of latitude $45^{\circ} \mathrm{N}$ and had dark pigmented skin. Danes had primarily Danish ancestry with the exception of three parents being from Sweden, The Faroe Islands and Northern Germany. They had relatively light melanized skin

${ }^{\mathrm{b}}$ Group difference between Immigrants and Danes (percentage compared to the Danes)

${ }^{\mathrm{c}}$ Statistical differences between the two groups tested with Mann-Whitney $U$ test (two-sided test). Boldface indicates statistical significance at $P<0.05$

${ }^{\mathrm{d}}$ Only days with available UVR measurement and diary data were analysed

${ }^{\text {e}}$ Body exposure is defined as exposing shoulders, upper body and/or sunbathing

${ }^{\mathrm{f}}$ Sun-exposed BSA is defined as the mean value of the maximal sun-exposed body surface area recorded daily. The accumulated UVR dose was adjusted for sun-exposed BSA by multiplication

\subsubsection{UVR doses per day and accumulated UVR doses}

Group I received a mean of 0.5 standard erythema dose (SED) [19] per day, while Group D received a mean dose of $1.3 \mathrm{SED}$ (mean difference: $0.8 \mathrm{SED}, P=1.3 \times 10^{-8}$ ). Thus, Group I received $62 \%$ less UVR $(0.8$ SED/1.3 SED) than Group D. In fact, Group I received lower UVR doses at all analysed time intervals $(07.00-12.00,12.00-15.00$ and 15.00-19.00) during daytime $\left(P \leq 1.4 \times 10^{-3}\right.$, data not shown). However, the daily timing of sun exposure (i.e., the distribution of mean UVR exposure in a given timeinterval compared to the accumulated UVR exposure during summer (\%) was very similar in both groups (Table 4). Compared to Group D, Group I received relatively more of their daily UVR $(4.8 \%$ of $47 \mathrm{SED}=2.3 \mathrm{SED}, P=0.02)$ between 12:00 to 15:00 when the UVB content is highest. As the difference between the two groups' accumulated UVR was 76 SED, the 2.3 SED is not likely to have made a significant difference and an estimate of UVB based on the measured erythema-weighted UVR was not performed. Furthermore, there was a strong linear relation (squared correlation coefficient, $R^{2}=0.999$ ) between the measured erythema-weighted UVR and UVB, indicating that UVR was representative for UVB.

On workdays, days off work, holidays, days abroad and on days with body exposure Group I received between 33 to $74 \%$ less UVR $(P \leq 0.011)$ than Group D.

Similar group differences in accumulated UVR during the study period were observed (47 SED vs 123 SED, Table 3). 
Table 4 Daily UVR dose and how it is distributed over the day for the two groups

\begin{tabular}{llll}
\hline & Immigrants $^{\mathrm{a}}$ & Danes $^{\mathrm{a}}$ & $P$ value $^{\mathrm{b}}$ \\
\hline UVR dose all day & $0.5 \mathrm{SED}$ & $1.3 \mathrm{SED}$ & - \\
Time interval & & & \\
07:00-12:00 & $23.7 \%$ & $25.3 \%$ & 0.14 \\
12:00-15:00 & $38.1 \%$ & $33.3 \%$ & $\mathbf{0 . 0 2}$ \\
15:00-19:00 & $38.2 \%$ & $41.4 \%$ & 0.06 \\
\hline
\end{tabular}

$U V R$ ultraviolet radiation

Percentages are calculated for each group separately and as the UVR received during a time interval/UVR dose all day. The percentages thus show the daily timing of sun exposure. Erythema-weighted UVR was measured with individual dosimeters

${ }^{a}$ Immigrants originated from countries south of latitude $45^{\circ} \mathrm{N}$ and had dark pigmented skin. Danes had primarily Danish ancestry with the exception of three parents being from Sweden, The Faroe Islands and Northern Germany. They had relatively light pigmented skin

${ }^{\mathrm{b}}$ Statistical differences between the two groups were tested with Fisher's test (two-sided test). Boldface indicates statistical significance at $P<0.05$

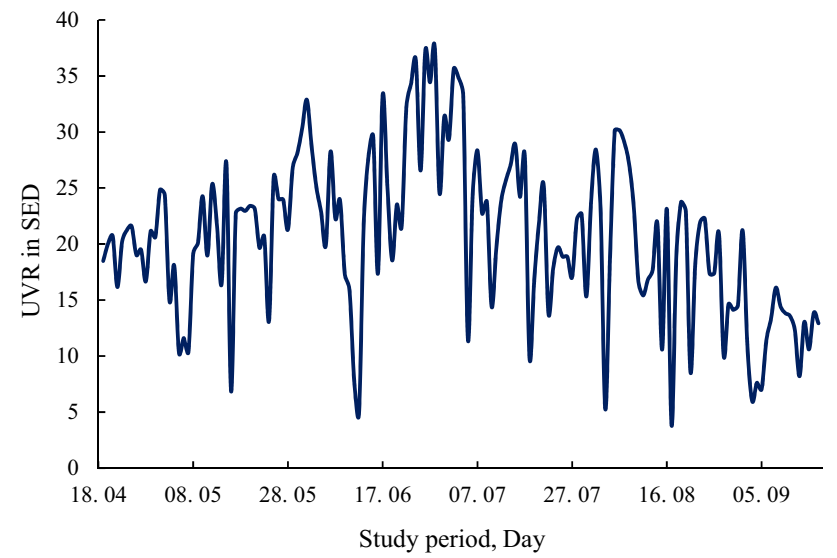

Fig. 1 Ambient and erythema-weighted UVR during study period. The blue curve shows the magnitude and variation of erythemaweighted UVR in Denmark during the study period

\subsubsection{Ambient UVR}

Mean daily ambient UVR during the study period is shown in Fig. 1. Figure 2a shows the course of the ambient UVR throughout a day in July and Fig. 2b shows the relation between ambient UVR and UVB. The mean ambient UVR dose in the study period was the same for both groups (21.5 SED, $P=0.11$ ). Group I received $2.2 \%$ and Group D received $5.8 \%$ of the ambient UVR $\left(P=1.2 \times 10^{-8}\right)$.

\subsubsection{Clothing, sun-exposed BSA and UVR}

Daily recorded clothing codes were translated into sunexposed BSA in accordance with Supplementary Table 1

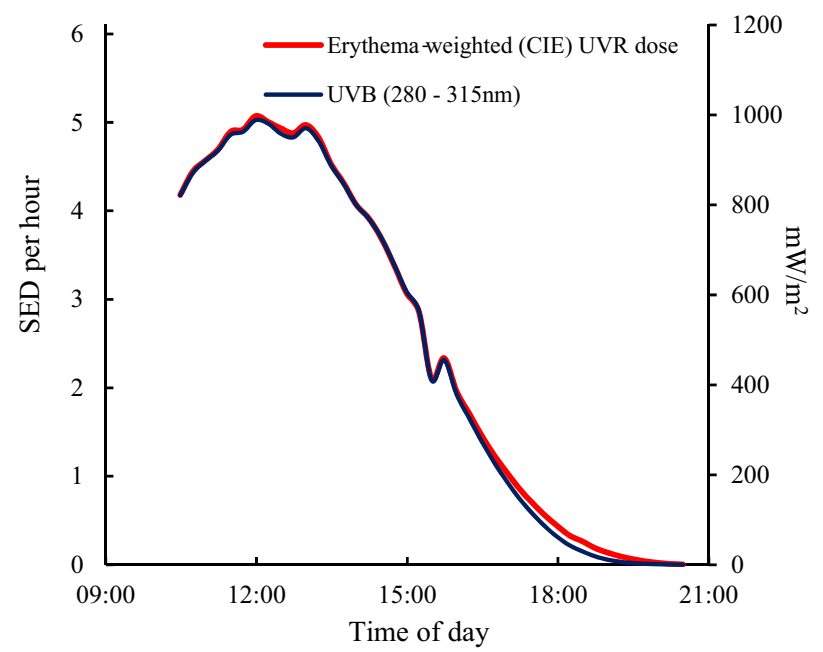

(a)

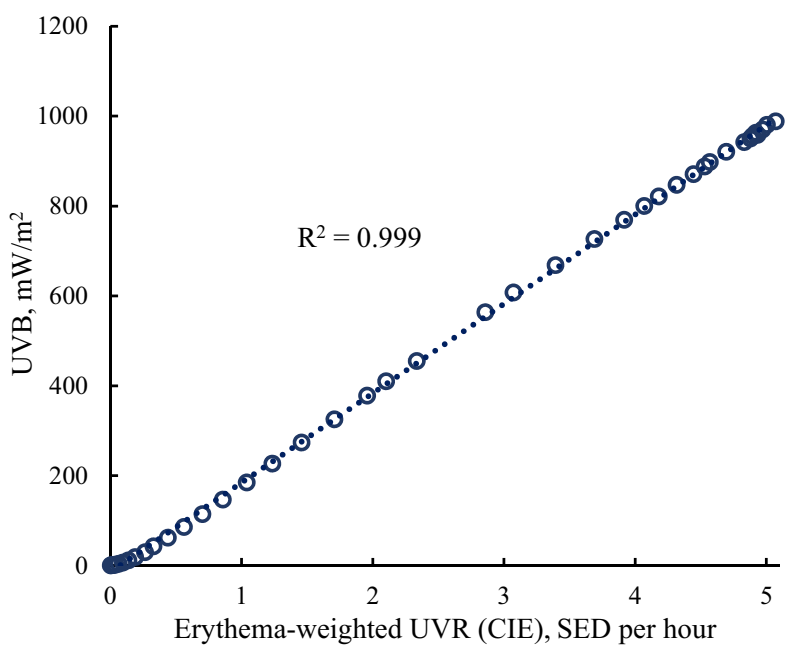

(b)

Fig. 2 a Daily distribution of erythema-weighted UVR and UVB. The daily distribution of dosimeter-measured erythema weighted UVR (CIE, red curve, primary $y$-axis) and the corresponding UVB (blue curve, secondary $y$-axis) measured during calibration of dosimeters (July) shows that the UVR and UVB are highest from around noon to 15:00, and that there is a close relation between UVR and UVB. b Relation between dosimeter-measured UVR and UVB measured during calibration. Dosimeter-measured erythema-weighted UVR is strongly and linearly related to UVB.

and Supplementary Figs. 1 and 2. Group I had a sunexposed BSA (mean maximal sun-exposed BSA) of $0.46 \mathrm{~m}^{2}$ (Table 3). This was $0.18 \mathrm{~m}^{2}\left(28 \%, P=6.5 \times 10^{-4}\right)$ less than the figure for Group D. This difference in sun-exposed BSA influences the received UVR dose to the skin and, therefore, also 25(OH)D production. Adjusting the UVR dose (joule, $\mathrm{J} / \mathrm{m}^{2}$ ) for the daily sun-exposed BSA $\left(\mathrm{m}^{2}\right)$ resulted in an accumulated UVR dose to the skin of $25 \mathrm{~J}$ for Group I, which was $70 \%$ less than the $82 \mathrm{~J}$ for Group D (difference: $\left.57 \mathrm{~J}, P=1.8 \times 10^{-9}\right)$. 


\subsection{5(OH)D levels before and after summer}

There was no significant difference in start levels of $25(\mathrm{OH}) \mathrm{D}$ before summer $(P=0.12$, Table 3$)$ between Group I (mean: $47 \mathrm{nmol} \mathrm{l}^{-1}$ ) and Group D (mean $55 \mathrm{nmol} \mathrm{l}^{-1}$ ). At study start, $67 \%$ of Group I and $49 \%$ of Group D had 25(OH)D levels below or equal to $50 \mathrm{nmol}^{-1}(P=0.16)$. At study end (after summer) the mean 25(OH)D levels were $55 \mathrm{nmol}^{-1}$ in Group I and $85 \mathrm{nmol}^{-1}$ in Group D $\left(P=5.4 \times 10^{-6}\right)$. Forty-five $\%$ of Group I and $7.7 \%$ of Group D then had 25(OH)D levels below $50 \mathrm{nmol} \mathrm{l}^{-1}\left(P=2.9 \times 10^{-4}\right)$. The mean increase in 25(OH)D was $8.7 \mathrm{nmol} \mathrm{l}^{-1}$ for Group I and $30 \mathrm{nmol} \mathrm{l}^{-1}$ for Group D (difference: $21.3 \mathrm{nmol} 1^{-1}, P=1.5 \times 10^{-4}$ ). Thus, Group I had a $71 \%$ smaller increase in $25(\mathrm{OH}) \mathrm{D}$ than Group D.

\subsection{UVR reactivity}

UVR reactivity was defined as the change in $25(\mathrm{OH}) \mathrm{D}$ over the summer per UVR dose (joule, J) received to the skin over the same period. In this context UVR reactivity is, consequently, the ability to increase $25(\mathrm{OH}) \mathrm{D}$ after exposure to $1 \mathrm{~J}$ of UVR. UVR reactivity is, therefore, a measure of the effectiveness of the UVR in inducing a $25(\mathrm{OH}) \mathrm{D}$ increase. Measured erythema-weighted UVR was used, instead of performing corrections to calculate UVB, as the daily timing of their sun exposure was similar in both participant groups and there was a strong $\left(R^{2}=0.999\right)$ linear relation between measured erythema-weighted UVR and UVB in the calibration data as described in the Method section.

As there was a major individual variation in the UVR dose received, the $25(\mathrm{OH}) \mathrm{D}$ increase was adjusted for accumulated UVR to the skin by calculating the UVR reactivity (defined as: $\Delta 25(\mathrm{OH}) \mathrm{D} / \mathrm{accumulated} \mathrm{UVR}$ to the skin). This was $0.53 \mathrm{nmol} \mathrm{l}^{-1} \mathrm{~J}^{-1}$ (range -5.8 to $6.0 \mathrm{nmol} \mathrm{l}^{-1} \mathrm{~J}^{-1}$ for Group I, similar $(P=0.62)$ to $0.63 \mathrm{nmol} \mathrm{l}^{-1} \mathrm{~J}^{-1}$ (range -0.11 to $3.2 \mathrm{nmol} \mathrm{l}^{-1} \mathrm{~J}^{-1}$ ) for Group D. There was no significant linear relation between facultative skin pigmentation (PPF) and UVR reactivity $(P=0.82$, Fig. 3$)$.

\subsection{Relation between 25(OH)D end levels and accumulated UVR to the skin}

Due to the similar UVR reactivity in both groups, the relation between $25(\mathrm{OH}) \mathrm{D}$ end level and accumulated UVR dose to the skin was investigated for the groups combined. This was done to explore if the differences in UVR exposure could explain the observed differences in $25(\mathrm{OH}) \mathrm{D}$ end levels. The relation was best described by a power model $\left(Y=B_{0} \times t^{B_{1}} \Leftrightarrow \operatorname{Ln}(Y)=\operatorname{Ln}\left(B_{0}\right)+\left(B_{1} \times \operatorname{Ln}(t)\right.\right.$,

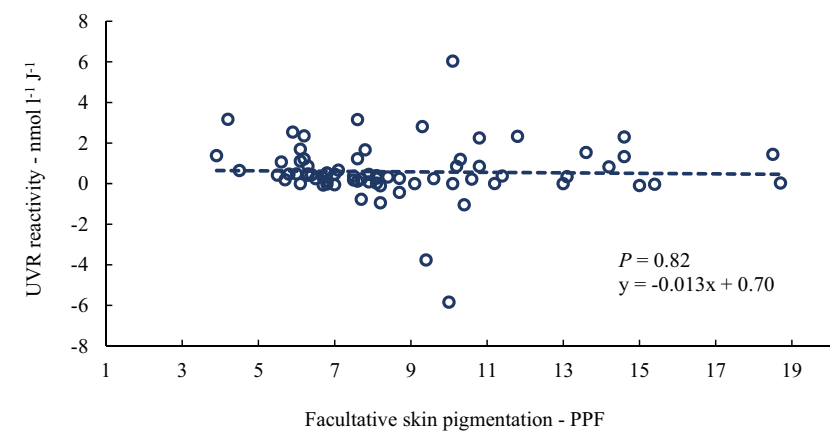

Fig. 3 Relation between facultative skin pigmentation and UVR reactivity. The UVR reactivity $(\Delta 25(\mathrm{OH}) \mathrm{D} /$ accumulated UVR $\times$ sunexposed BSA, joule to the skin, $y$-axis) for the whole material is not influenced by facultative skin pigmentation (PPF, $x$-axis)

Table 5 Relations between 25(OH)D end levels and UVR

\begin{tabular}{llll}
\hline & $R^{2}$ & $R^{2}$ increase $^{\mathrm{c}}$ & $P$ value $^{\mathrm{d}}$ \\
\hline $\begin{array}{l}\text { Best model } \\
\text { Ln }(\mathrm{UVR} \times \text { sun-exposed BSA })^{\mathrm{a}}\end{array}$ & 0.288 & & \\
$\mathrm{Ln}(\mathrm{UVR} \times$ sun-exposed BSA $)$ & 0.567 & $0.279^{3}$ & $\mathbf{1 . 2} \times \mathbf{1 0}^{-\mathbf{6}}$ \\
$\quad \begin{array}{l}\text { with } 25(\mathrm{OH}) \mathrm{D} \text { start level }(\text { base } \\
\text { model }^{\mathrm{b}}\end{array}$ & & &
\end{tabular}

Separate influence of demographic parameters

$\begin{array}{lll}\text { Base model } & 0.567 & 2.9 \times 10^{-13}\end{array}$

Added demographic parameters to base model ${ }^{\mathrm{e}}$ :

$\begin{array}{lcll}\text { Fitzpatrick's skin-type } & 0.651 & 0.084 & \mathbf{0 . 0 1 5} \\ \text { Facultative PPF } & 0.605 & 0.038 & \mathbf{0 . 0 1 2} \\ \text { Height } & 0.602 & 0.035 & \mathbf{0 . 0 1 7} \\ \text { Constitutive PPF } & 0.599 & 0.032 & \mathbf{0 . 0 2 3} \\ \text { Weight } & - & & 0.17 \\ \text { Sex } & - & & 0.39 \\ \text { Daily meals of fatty fish } & - & & 0.50 \\ \text { Age } & - & & 0.86 \\ \text { BMI } & - & & 0.98\end{array}$

Combined analysis of demographic parameters

$\begin{array}{llll}\text { Height and constitutive PPF } & 0.636 & 0.069 & \mathbf{4 . 4} \times \mathbf{1 0}^{\mathbf{- 1 4}}\end{array}$

$U V R$ ultraviolet radiation, $B S A$ body surface area, $R^{2}$ squared correlation coefficient, $P P F$ skin pigmentation protection factor, $B M I$ body mass index. The power model explained the relation between $25(\mathrm{OH})$ $\mathrm{D}$ end levels and accumulated UVR best and was linearized by double logarithm transformation

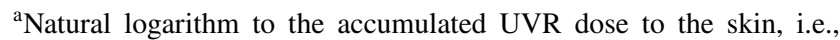
adjusted for sun-exposed BSA

${ }^{\mathrm{b}}$ This model was selected as a base model for investigation of individual demographic parameters

${ }^{\mathrm{c}}$ Calculated in comparison to $R^{2}$ value of the model including UVR $\times$ sun-exposed BSA

${ }^{\mathrm{d}} P$ values calculated by general linear models. Boldface indicates statistical significance at $P<0.05$

${ }^{\mathrm{e}}$ All demographic parameters were measured or assessed at study start except for meals of fatty fish that was recorded daily and facultative PPF that was a mean value of measurement at study start and study end 


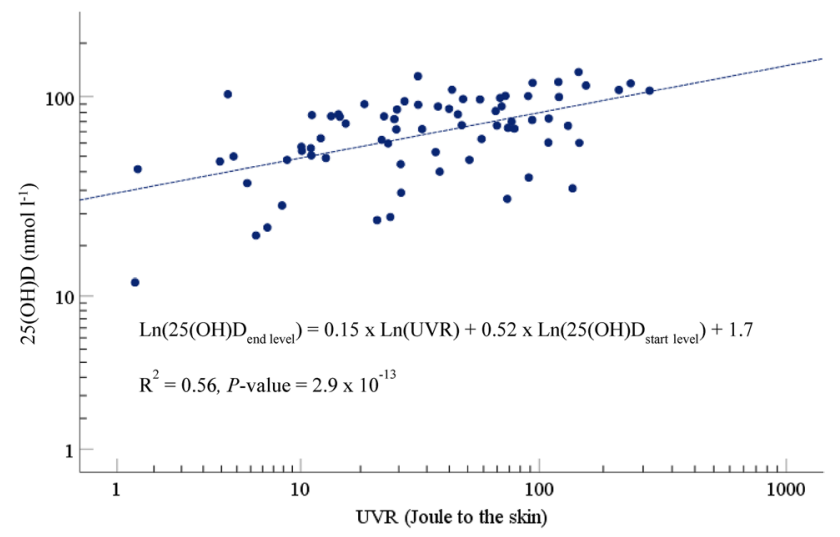

Fig. 4 Relation between 25(OH)D end levels and UVR. Natural logarithm was applied to $25(\mathrm{OH}) \mathrm{D}$ end level after summer (y-axis) and to accumulated UVR dose to the skin (i.e., adjusted for sun-exposed BSA, erythema energy to the skin in J, $x$-axis) in the whole material

$R^{2}=0.288, P=1.2 \times 10^{-6}$, Table 5), where UVR explained $28.8 \%$ of the variation in $25(\mathrm{OH}) \mathrm{D}$ end level.

To obtain linearity, natural logarithm was applied to 25(OH)D end levels and to the accumulated UVR doses to the skin (Fig. 4). The logarithm-transformed relation was investigated using general linear models (GLMs). The influence of 25(OH)D start level is well described [12] and it contributed with additionally $0.279(0.567-0.288$, Table 5) to the $R^{2}$ value. This model explained $56.7 \%$ of the variation and was used as a base model to investigate the individual influence of demographic parameters on the relation (Table 5).

\subsection{Influence of demographic parameters}

The separate influence of demographic parameters (Table 5) on the relation between 25(OH)D end levels and UVR dose to the skin in the groups combined was also investigated. Height influenced the relation significantly (increase in $R^{2}=0.035, P=0.017$ ), while weight, BMI, age, sex and daily intake of fatty fish did not $(P \geq 0.17)$. The three related parameters, Fitzpatrick skin type (increase in $R^{2}=0.084, P=0.015$ ), facultative PPF (increase in $R^{2}=0.038, P=0.012$ ) and constitutive PPF (increase in $R^{2}=0.032, P=0.023$ ) had a separate significant influence on the relation. Fitzpatrick skin type was not investigated further as it is a subjective assessment, representing skin pigmentation, cultural behaviour and, possibly, genetic factors. PPF was used to represent pigmentation. The combination of height and constitutive PPF in addition to UVR and $25(\mathrm{OH}) \mathrm{D}$ start level provided the best model $\left(R^{2}=0.636, P=4.4 \times 10^{-14}\right.$, Table 5) explaining $63.6 \%$ of the relation.

\section{Conclusions and discussion}

This study focused mainly on investigating sun exposure behaviour, sun-exposed BSA habits and 25(OH)D level in a group of 'immigrants` with dark pigmented skin and a group of 'Danes` with relatively light pigmented skin. We were able to provide real life and objectively measured personal solar UVR doses combined with daily selfreported clothing that was translated into sun-exposed BSA. Personal UVR was measured in SED every $5^{\text {th }}$ second and an average of the measurements was registered every $5 \mathrm{~min}$. (time-stamped doses). UVR was measured during late spring and summer in Denmark. At this time of year most solar-induced $25(\mathrm{OH}) \mathrm{D}$ production occurs, since from autumn to spring in Denmark sun-exposed body areas are usually limited to the face and hands, areas not sufficient to produce a significant increase in $25(\mathrm{OH})$ D [20-22].

UVR reactivity.

Solar UVR exposure of a person is influenced by geographic location, atmospheric conditions, timing and duration of solar exposure and the size of the BSA exposed to the sun. In addition, sun-induced vitamin D is also influenced by a person's age, BMI and, possibly, skin pigmentation of the sun-exposed BSA [23, 24]. In this study the immigrants and Danes resided in the same geographic region with identical atmospheric conditions and had almost the same timing of their solar UVR exposure doses. They had similar age and differed minimally in BMI. Thus, the majority of parameters normally influencing sun-induced $25(\mathrm{OH}) \mathrm{D}$ were similar. This was most likely reflected in the similar UVR reactivity. As many of the common influential parameters were similar in both groups, there was an amplified focus on investigating the influence of the parameters that differed in the two groups, i.e., sun behaviour, solar-exposed BSA, solar UVR exposure habits, $25(\mathrm{OH}) \mathrm{D}$ increase and skin pigmentation.

UVR vs UVB.

The electronic dosimeters measured erythema-weighted UVR (CIE) in SED containing both UVB $(280 \mathrm{~nm}$ to $315 \mathrm{~nm}$ ) and UVA ( $315 \mathrm{~nm}$ to $400 \mathrm{~nm}$ ) as the general risk of exposure is related to this parameter. Only UVB exposure is related to vitamin D production in the skin. Using erythema-weighted UVR doses could, therefore, potentially influence the results related to vitamin D. However, as the daily timing of UVR exposure was similar in both groups, and there was a strong linear relation between the measured UVR and the UVB content, correction of the UVR data was not necessary.

Behavioural differences.

Behaviourwise, the immigrants reported less than half as many days with body exposure, on a beach and with 
sunburns. They received $70 \%$ less UVR. This clearly indicates that the immigrants are far less sun-seeking. This was similarly reflected on days at work, but much more pronounced on days off work, holidays, days abroad and days with body exposure. Furthermore, the immigrants had a considerably lower sun-exposed BSA. This is consistent with the report from Dlova et al. and Shroff et al. that people from Asia and Africa widely use skin-lightening practices, as these populations may prefer lighter skin $[25,26]$. This notion may lead to active avoidance of sun light exposure [27].

Parameters influencing 25(OH)D level after summer.

The mean 25(OH)D increase was substantially lower (71\%) for the immigrants than for the Danes, despite their similar ability to produce UVR-induced $25(\mathrm{OH}) \mathrm{D}$. In the groups combined, the $25(\mathrm{OH}) \mathrm{D}$ level after summer was mainly and equally influenced by accumulated UVR dose to the skin and $25(\mathrm{OH}) \mathrm{D}$ level in late spring. Combined they explained $56.7 \%$ of the variation. In addition, height had a minor influence of $3.5 \%$. Not facultative PPF (i.e., the pigmentation of the skin exposed to sun), but constitutive PPF (i.e., the skin pigmentation on buttocks and normally not exposed to sun) had a small influence of $3.2 \%$. This finding is consistent with our previous results in a controlled UVR study of light-skinned and dark-skinned persons [13, 14]. In these studies, the influence of constitutive PPF could essentially be ascribed to genetic factors rather than skin pigmentation itself as the influence of constitutive PPF was exceeded and replaced by the influence of pigment genes $[14,23]$. As we did not test for pigment genes in this study, it is unknown how much of this influence may be ascribed to genetic factors. Again, this was to be expected and consistent with the findings of Young et al. as $79 \%$ of the participants in the immigrant group had intermediate pigmented skin and only $21 \%$ had black skin [23].

As shown in Fig. 4, the 25(OH)D end level as a response to UVR displays major individual variation which is why it was only possible to explain $63.6 \%$ of the variation. During summer with abundant solar UVR, dietary vitamin $\mathrm{D}$, age and BMI did not influence 25(OH)D increase in real life situations. This is most likely because in Denmark the natural dietary supply of vitamin $\mathrm{D}$ is very low and less than $3 \mu \mathrm{g}$ (120 IU) per day [28], and no food is fortified with vitamin D. In addition, the participants were too similar in age and BMI. Sunscreen use was not corrected for as there were relatively few days with sunscreen use, and sunscreen quantity and the BSA it was applied to were not reported. Thus, sunscreen use and functional genetic variation in the metabolism of vitamin D could substitute other potentially influential parameters explaining some of the $36.4 \%$ of the variation that was not explained in this study.

Previous studies have used personal solar UVR estimates based on ambient measurement or measurements by UVR badges worn for 1-2 weeks during a 3-month study period [29-32]. Only one of these studies [29] has concurrently addressed the issue of poor $25(\mathrm{OH}) \mathrm{D}$ status in immigrants (176 South Asians, Fitzpatrick skin type V) in the UK. In that study the daily summer UVR doses were approximately 0.7 SED for the South Asians and 1.4 SED for the whites, similar to those measured in our study (0.5 SED and 1.3 SED, respectively).

Unexpectedly, our immigrants had a relatively high $25(\mathrm{OH}) \mathrm{D}$ level before summer $\left(47 \mathrm{nmol}^{-1}\right)$. In comparison, others have reported 25(OH)D levels between 16 to $33 \mathrm{nmol}^{-1}$ for darker pigmented immigrants between January to May living on a similar latitude [33, 34]. As none of the immigrants in this study wore a veil or burka, this could provide some explanation. Furthermore, they were primarily recruited among hospital employees and were very much aware of the risk of low $25(\mathrm{OH}) \mathrm{D}$ status and several had been taking vitamin D supplements during winter. Nonetheless, a large proportion $(67 \%)$ still had $25(\mathrm{OH})$ $\mathrm{D}$ levels below $50 \mathrm{nmol}^{-1}$ before summer. After summer, $45 \%$ still had 25(OH)D levels below $50 \mathrm{nmol}^{-1}$ compared to $7.7 \%$ of Danes. Thus, a much larger proportion of the immigrants will not be able to maintain a winter $25(\mathrm{OH}) \mathrm{D}$ level above $50 \mathrm{nmol}^{-1}$ with their UVR exposure behaviour. The 25(OH)D levels of the Danes in this study were representative of what others have reported [35].

This study was limited by the calculation of sun-exposed BSA, which did not account for body shape. Moreover, clothing was only reported once daily. This practice was chosen to avoid the negative effect on compliance of more exhaustive reporting. In addition, less intervention leads to less change of normal behaviour. Still, this approach introduces some uncertainty to the calculation of the daily UVR dose to the skin. A study by Heerfordt et al. found that between noon and 3 p.m. when the UVR is strongest, $90 \%$ of beachgoers wear minimal clothing (swimwear) [36]. Therefore, when the UVR is strongest and the temperature is highest, people wear the least clothes and expose a maximal BSA to the sun. This minimizes the introduced some uncertainty. Another limitation of this study was the relatively small number of 25(OH)D samples. More frequent sampling could have provided a better description of the development in $25(\mathrm{OH}) \mathrm{D}$ over summer including at which time $25(\mathrm{OH})$ $\mathrm{D}$ was maximal.

Overall, in the process of understanding the basis for the inferior 25(OH)D status in immigrants with dark pigmented skin, the role of skin pigmentation has received much focus in comparison to sun exposure and clothing habits. In this study sun exposure and clothing habits along with $25(\mathrm{OH})$ $\mathrm{D}$ start level have proven to be much stronger determinants of $25(\mathrm{OH}) \mathrm{D}$ level after summer than skin pigmentation. As $25(\mathrm{OH}) \mathrm{D}$ start level is dependent on the sun exposure from the previous year, this is in principle also influenced 
by long-term sun exposure habits. Moreover, 25(OH)D start level is influenced by supplements taken during the previous winter. Even for persons taking vitamin D supplement of as much as $50 \mu \mathrm{g}(2000 \mathrm{IU})$ per day, solar UVR is still an important contributor to overall 25(OH)D status [32] and signifies the importance of solar UVR on vitamin D status.

Given (1) the previous work in this field, (2) the summer season during which the majority of vitamin D storages are filled, (3) the similar UVR reactivity with no influence of facultative PPF and (4) the found differences in clothing habits/sun-exposed BSA and in exposed UVR doses between the groups, it could be expected that the influence of skin pigmentation on UVR-induced $25(\mathrm{OH}) \mathrm{D}$ increase was negligible in real life [12-15].

In conclusion, despite similar UVR reactivity, the immigrants with dark pigmented skin had much lower 25(OH)D increase, lower 25(OH)D level after summer, lower daily and accumulated UVR exposure and less sun-exposed BSA than the light-skinned Danes during a summer season. 25(OH)D level after summer was mainly influenced by UVR exposure and clothing habits.

\section{Materials and methods}

\subsection{Study design, ethical approval and informed consent}

This was a prospective, observational and single-centre study of participants living within $100 \mathrm{~km}$ of Bispebjerg Hospital, University of Copenhagen, Denmark $\left(55.7^{\circ} \mathrm{N}\right)$. The study was conducted from late April to the beginning of September in 2010. Written, informed consent was obtained from all participants. Study protocol (H-C-2008-097) was approved by the Committees for Biomedical Research Ethics for the Capital Region in Denmark and completed in accordance with the Declaration of Helsinki.

\subsection{Participants}

Seventy-seven healthy participants were included in this study. Of these, 72 had sufficient data that could be analysed and were investigated further. Thirty-three participants (immigrants) with dark pigmented skin had self-reported ancestors originating from countries located south of latitude $45^{\circ} \mathrm{N}$ (Pakistan, India, Sri Lanka, Thailand, Philippines, Korea, Gambia, Uganda, St. Martinique, Afghanistan, Palestine, Kurdistan, Turkey, Montenegro, Macedonia, Russia and Ukraine). Thirty-nine participants self-reported their origin being primarily from Denmark (Danes). The exceptions were three parents originating from other Northern European countries (Sweden, The Faroe Islands and Northern Germany). All had relatively light pigmented skin.
Twenty-nine of the Danes had been included as controls in a previous study [37].

In this study, we examined vitamin D levels in samples of relatively darkly pigmented, mostly immigrant people resident in Denmark and lightly pigmented people, mostly native to Denmark. We have designated these samples as "Immigrants" and "Danes," respectively. We recognize that no classification of people is ideal or without possible pejorative connotations. The names given to these samples was as simple and descriptive as possible, without using racial typologies or characterizations.

The inclusion criterion was: (1) age 18-75. The exclusion criteria were (1) supplementary vitamin D intake exceeding $10 \mu \mathrm{g}$ (400 IU) per day 1 month prior to study start; (2) use of supplementary vitamin D during study period; (3) sun holiday south of latitude $45^{\circ} \mathrm{N} 1$ month prior to the study period; (4) use of solarium 1 month prior to or during the study period; (5) chronic disease; (6) skin disease; (7) intake of cholesterol-lowering or photosensitizing medication; (8) pregnancy; (9) drug addiction; (10) psychiatric disorder; and (11) physical disabilities. Participants were recruited from the Danish Central Population Registry or among employees at the hospital or among friends of the authors. To ensure uniformity in examination, assessments and instructions of participants at study start and study end, all study visits were performed by the same person. As each visit lasted more than an hour, all participants were not able to start and end the study at the exact same date but were enrolled over a period.

\subsection{Skin pigmentation}

Objective measurement of skin pigmentation (pigment protection factor, PPF) was performed non-invasively with a skin reflectance meter (UV-Optimize Scientific, Chromolight, Vedbaek, Denmark) [38]. PPF is linearly related to the content of eumelanin and pheomelanin in epidermal biopsies [38-40]. The measuring range of PPF is $1-25$, meaning that a UVR dose between 1 and 25 SED is needed to elicit a just perceptible erythema. Constitutive PPF was measured on the buttocks at study start. Facultative PPF represented a mean of the measurements at study start and end on the back of the shoulders. A more detailed method is described elsewhere [14].

\subsection{Personal electronic UVR dosimeter, SunSaver}

The participants wore personal electronic UVR dosimeters mounted into a casing also containing a digital watch, so that they could be used as wristwatches (SunSaver). Participants were instructed to wear the SunSaver on their wrist when they were outdoors between 07:00 $\mathrm{h}$ and 19:00 $\mathrm{h}$. The UVR dosimeter contains a UVR sensor (sensitivity 
range: $200-400 \mathrm{~nm}$ corresponding to the erythema action spectrum), a temperature sensor and a data logger. The data logger was set to measure every 5 th second and to store an average of the UVR and temperature measurements every $5 \mathrm{~min}$. The measurement range of the dosimeter is 0.07-47.81 SED per hour and the sensitivity is 0.07 SED per hour [18]. The dosimeters were calibrated against a double-grating spectroradiometer DM150 (Bentham, Reading, U.K.), using the sun as a light source. Timestamped temperature measurements were used to evaluate compliance. The dosimeter is described in full by Heydenreich et al. [17, 18].

The SunSavers measured erythema-weighted UVR containing both UVB (280-315 nm) and UVA (315-400 nm). The general risk of exposure is related to UVR exposure. Only UVB exposure is related to vitamin D production in the skin. Data from calibration of the SunSavers (performed by Public Health England, former HPA, [41]) show that the distribution of erythema-weighted UVR is closely related to the corresponding UVB during a day in July, as shown in Fig. 2a [19]. In Fig. 2b, the relation between erythema-weighted UVR and UVB is plotted, showing a strong linear relation $\left(R^{2}=0.999\right)$. Thus, erythema-weighted UVR is representative of UVB and does not impact the overall results related to vitamin $\mathrm{D}$ in this study. Furthermore, the two participant groups had very a similar distribution of mean UVR exposure during the day in percent of their accumulated UVR exposure during summer. Against this background, a calculation of UVB based on the measured erythema-weighted UVR was not considered necessary.

\subsection{Diary data}

In a questionnaire-based diary the participants were asked daily to answer 'yes' or 'no' to eight questions regarding their sun behaviour [37]. In addition, participants were instructed to select a sex-specific code from a pictogram that represented the least clothing they had worn that day (Supplementary Fig. 1). The clothing codes were translated into the maximal sun-exposed BSA in $\mathrm{m}^{2}$ [42] based on BSA estimates of clothing presented in Supplementary Table 1, Supplementary Figs. 1 and 2 [43]. The accumulated UVR dose (unit: $\mathrm{J} / \mathrm{m}^{2}$ ) was multiplied by the maximal sun-exposed BSA (unit: $\mathrm{m}^{2}$ ) to provide a more accurate measure of the actually received UVR dose to the skin (unit: joule). Participants were also instructed to daily record the number of fatty fish meals consumed, and a mean individual intake of fatty fish meals was used in the analysis. Vitamin D-fortified food is not available in Denmark. At the end of each month the diaries were scrutinized and corrected for errors immediately after collection.

\subsection{Compliance, data collection and data analysis}

Inclusion of a participant in the final data analysis required at least 30 days of dosimeter measurements with corresponding diary data. Five participants were not included due to lack of compliance or a defective dosimeter and consequently an insufficient number of days available for analysis. The remaining participants had a $100 \%$ compliance of 25(OH)D sampling. The total number of study days between first and last 25(OH)D sample was 8610 days. Diary data were missing from 66 days $(0.77 \%)$. UVR data were missing from 529 days (6.1\%). In the remaining 8015 study days, the participants had answered no to wearing the SunSaver for 1010 days (12\%) and yes to wearing the SunSaver for 7005 days (81\%). The UVR data for these 7005 days were crosschecked with data from the diaries for validation. If a participant had answered yes to wearing the SunSaver but the dosimeter had measured 0 SED for a given day, the data from the temperature sensor were used to confirm if the participant had worn the SunSaver. Furthermore, if the diary indicated body exposure along with an UVR dose of 0 SED or if a participant answered 'yes' to sunbathing, but the dosimeter had measured $<15 \mathrm{~min}$. on a given day, we considered this an error in filling in the diary. This resulted in 338 days (3.9\%) being left out. Thus, 6667 days were available for analysis (77\%).

\subsection{Blood analysis}

Serum 25-hydroxyvitamin $\mathrm{D}_{3}$ was analysed at study start and end on a liquid chromatography tandem mass spectrometer (LC-MS/MS) [12, 20]. To minimize analysis variance, at least triplet analyses (technical replicates) were performed and all 25(OH)D samples from the same participant were analysed in one batch. The total relative standard deviation (SD) varied between $4.9 \%$ at $20 \mathrm{nmol}^{-1}$ and $14.1 \%$ at $222 \mathrm{nmol}^{-1}$ reflecting experimental variability. This method has been validated through an independent laboratory (Department of Clinical Chemistry, Birmingham City Hospital, UK), a Clinical Pathology Accreditation Laboratory and a member of the Vitamin D External Quality assessment scheme. Linear regression of 25(OH)D analyses of identical samples showed a strong correlation $\left(\mathrm{R}^{2}=0.91\right)$ with a slope of 1.01 [44].

\subsection{Statistical analysis}

The majority part of the data was not normally distributed. Therefore, the non-parametric Mann-Whitney $U$ test (unpaired) was used to statistically test group differences in continuous variables. For categorical variables, 
Pearson's $\mathrm{Chi}^{2}$ or Fisher's test was used. All tests were two-tailed.

The relation between accumulated UVR dose to the skin and $25(\mathrm{OH}) \mathrm{D}$ end level (GLM, $\left.R^{2}=0.36\right)$ rather than the $\Delta 25(\mathrm{OH}) \mathrm{D}$ (GLM, $R^{2}=0.11$ ) was subjected to investigation, as this relation proved to be stronger. The $25(\mathrm{OH}) \mathrm{D}$ end level was significantly influenced by the $25(\mathrm{OH}) \mathrm{D}$ start level (GLM, $R^{2}=0.362, P=2.3 \times 10^{-8}$ ). Therefore, the relation between the 25(OH)D end level and the accumulated UVR dose to the skin includes the $25(\mathrm{OH}) \mathrm{D}$ start level.

To describe the relation between $25(\mathrm{OH}) \mathrm{D}$ end level and the mean accumulated UVR exposure doses to the skin, the following models were investigated: linear, inverse, power, logarithmic and exponential. The power model provided the best fit and was linearized by applying logarithm to $25(\mathrm{OH})$ $\mathrm{D}$ and UVR. It was then investigated with GLMs (sum of squares type I). The significant influence of the natural logarithm to $25(\mathrm{OH}) \mathrm{D}$ start level was included in this model. Subsequently, the separate influence of demographic parameters on the relation between 25(OH)D end level and UVR was investigated. Parameters with significant influence were selected for further investigation.

Data were statistically analysed using SPSS 24.0 for Windows (SPSS Inc., Chicago, IL, U.S.A.). $P<0.05$ was considered significant.

Supplementary Information The online version contains supplementary material available at https://doi.org/10.1007/s43630-021-00115-w.

Acknowledgements The authors thank the participants for taking part in this study and Bispebjerg Hospital, University of Copenhagen for support and Jakob Heydenreich for instructions in preparing/handling the SunSavers and occasional assistance in downloading data.

Author contributions Conceptualization: HCW, PAP, PD; Material preparation and data collection: PD, LWI; Formal analysis and investigation: PD, PAP; Preparation of first draft of manuscript: PD, Editing manuscript: PD, HCW, PAP, LWI; Supervision: HCW, PAP. All authors read and approved the final manuscript.

Data availability Data sets analysed during the current study are available from the corresponding author on reasonable request.

\section{Declarations}

Conflict of interests The authors state no conflict of interest.

\section{References}

1. Norval, M., Björn, L. O., \& de Gruijl, F. R. (2010). Is the action spectrum for the UV-induced production of previtamin D3 in human skin correct? Photochemical Photobiological Science, 9(1), 11-17.

2. Karsten, A. E., \& Smit, J. E. (2012). Modeling and verification of melanin concentration on human skin type. Photochemistry and Photobiology, 88(2), 469-474.
3. Young, A. R. (1997). Chromophores in human skin. Physics in Medicine \& Biology, 42(5), 789-802.

4. Meredith, P., \& Riesz, J. (2004). Radiative relaxation quantum yields for synthetic eumelanin. Photochemistry and Photobiology, 79(2), 211-216. https://doi.org/10.1562/0031-8655(2004)079

5. Fajuyigbe, D., \& Young, A. R. (2016). The impact of skin colour on human photobiological responses. Pigment Cell \& Melanoma Research, 29(6), 607-618.

6. Fajuyigbe, D., Lwin, S. M., Diffey, B. L., Baker, R., Tobin, D. J., Sarkany, R. P. E., \& Young, A. R. (2018). Melanin distribution in human epidermis affords localized protection against DNA photodamage and concurs with skin cancer incidence difference in extreme phototypes. FASEB Journal, 29, 607-618.

7. Norval, M., Kellett, P., \& Wright, C. Y. (2014). The incidence and body site of skin cancers in the population groups of South Africa. Photodermatology, Photoimmunology and Photomedicine, 30(5), 262-265.

8. Lips, P. (2007). Vitamin D status and nutrition in Europe and Asia. Journal of Steroid Biochemistry and Molecular Biology, 103(3-5), 620-625. https://doi.org/10.1016/j.jsbmb.2006.12.076

9. Farrar, M. D., Webb, A. R., Kift, R., Durkin, M. T., Allan, D., Herbert, A., Berry, J. L., et al. (2013). Efficacy of a dose range of simulated sunlight exposures in raising vitamin D status in South Asian adults: Implications for targeted guidance on sun exposure. American Journal of Clinical Nutrition, 97(6), 1210-1216. https:// doi.org/10.3945/ajen.112.052639

10. Hakim, O. A., Hart, K., McCabe, P., Berry, J., Francesca, R., Rhodes, L. E., Spyrou, N., et al. (2016). Vitamin D production in UK Caucasian and South Asian women following UVR exposure. Journal of Steroid Biochemistry and Molecular Biology, 164(1), 223-229. https://doi.org/10.1016/j.jsbmb.2016.03.025

11. Norval, M., \& Wulf, H. C. (2009). Does chronic sunscreen use reduce vitamin D production to insufficient levels? The British Journal of Dermatology, 161(4), 732-736. https://doi.org/10. 1111/j.1365-2133.2009.09332.x

12. Bogh, M. K., Schmedes, A. V., Philipsen, P. A., Thieden, E., \& Wulf, H. C. (2010). Vitamin D production after UVB exposure depends on baseline vitamin $\mathrm{D}$ and total cholesterol but not on skin pigmentation. Journal of Investigative Dermatology, 26(1), 546-553. https://doi.org/10.1038/jid.2009.323

13. Datta, P., Philipsen, P. A., Olsen, P., Petersen, B., Johansen, P., Morling, N., \& Wulf, H. C. (2016). Major inter-personal variation in the increase and maximal level of 25-hydroxy vitamin D induced by UVB. Photochemical \& Photobiological Sciences, 15(4), 536-545. https://doi.org/10.1039/c5pp00462d

14. Datta, P., Philipsen, P. A., Olsen, P., Petersen, B., Andersen, J. D., Morling, N., \& Wulf, H. C. (2019). Pigment genes not skin pigmentation affect UVB-induced vitamin D. Photochemical \& Photobiological Sciences. https://doi.org/10.1039/c8pp00320c

15. Young, A. R., Morgan, K. A., Ho, T. W., Ojimba, N., Harrison, G. I., Lawrence, K. P., Jakharia-Shah, N., et al. (2020). Melanin has a small inhibitory effect on cutaneous vitamin D synthesis: A comparison of extreme phenotypes. The Journal of Investigative Dermatology, 140(7), 1418-1426. https://doi.org/10.1016/j.jid. 2019.11.019

16. Gutiérrez, O. M., Farwell, W. R., Kermah, D., \& Taylor, E. N. (2011). Racial differences in the relationship between vitamin D, bone mineral density, and parathyroid hormone in the National Health and Nutrition Examination Survey. Osteoporosis International, 22(6), 1745-1753.

17. Heydenreich, J., \& Wulf, H. C. (2019). Personal electronic UVR dosimeter measurements: Specific and general uncertainties. Photochemical \& Photobiological Sciences, 18(6), 1461-1470. https://doi.org/10.1039/C8PP00379C

18. Heydenreich, J., \& Wulf, H. C. (2005). Miniature personal electronic UVR dosimeter with erythema response and time-stamped 
readings in a wristwatch. Photochemistry and Photobiology, 81(5), 1138-1144. https://doi.org/10.1562/2004-11-22-RA-376

19. Commision Internationale de l'Eclairage (CIE) (1997). Standard erythema dose. 1251-5.

20. Datta, P., Bogh, M. K., Olsen, P., Eriksen, P., Schmedes, A. V., Grage, M. M., Philipsen, P. A., et al. (2012). Increase in serum 25-hydroxyvitamin- $\mathrm{D}(3)$ in humans after solar exposure under natural conditions compared to artificial UVB exposure of hands and face. Photochemical \& Photobiological Sciences, 11(12), 1817-1824. https://doi.org/10.1039/c2pp25093d

21. Datta, P., Philipsen, P. A., Olsen, P., Bogh, M. K., Johansen, P., Schmedes, A. V., Morling, N., et al. (2017). The half-life of $25(\mathrm{OH}) \mathrm{D}$ after UVB exposure depends on gender and vitamin D receptor polymorphism but mainly on the start level. Photochemical \& Photobiological Sciences, 16(6), 985-995. https://doi.org/ 10.1039/c6pp00258g

22. Webb, A. R., Kline, L., \& Holick, M. F. (1988). Influence of season and latitude on the cutaneous synthesis of vitamin D3: exposure to winter sunlight in Boston and Edmonton will not promote vitamin D3 synthesis in human skin. Journal of Clinical Endocrinology \& Metabolism, 67(2), 373-378. https://doi.org/10. 1210/jcem-67-2-373

23. Young, A. R., Morgan, K. A., Ho, T. W., Ojimba, N., Harrison, G. I., Lawrence, K. P., Jakharia-Shah, N., et al. (2019). Melanin has a small inhibitory effect on cutaneous vitamin D synthesis: a comparison of extreme phenotypes. The Journal of investigative dermatology, 140, 1418-1426. S0022-S202X. 31883961[pmid].

24. Need, A. G., Morris, H. A., Horowitz, M., \& Nordin, C. (1993). Effects of skin thickness, age, body fat, and sunlight on serum 25-hydroxyvitamin D. American Journal of Clinical Nutrition, 58(6), 882-885.

25. Shroff, H., Diedrichs, P. C., \& Craddock, N. (2017). Skin color, cultural capital, and beauty products: an investigation of the use of skin fairness products in Mumbai, India. Frontiers in Public Health, 5, 365

26. Dlova, N. C., Hamed, S. H., Tsoka-Gwegweni, J., \& Grobler, A. (2015). Skin lightening practices: An epidemiological study of South African women of African and Indian ancestries. The British Journal of Dermatology, 173(Suppl), 22-29.

27. Jang, H., Koo, F. K., Ke, L., Clemson, L., Cant, R., Fraser, D. R., Seibel, M. J., et al. (2013). Culture and sun exposure in immigrant East Asian women living in Australia. Women and Health, 53(5), 504-518.

28. Pedersen, A. N., Fagt, S., Groth, M. V., Christensen, T., BiltoftJensen, A., Matthiesen, J., Andersen, N. L., et al. (2010). Danskernes kostvaner 2003-2008 (Diets of Danes 2003-2008) (pp. 1-200). Technical University of Denmark.

29. Kift, R., Rhodes, L. E., Farrar, M. D., \& Webb, A. R. (2018). Is sunlight exposure enough to avoid wintertime vitamin D deficiency in United Kingdom Population Groups? International Journal of Environmental Research and Public Health, 15(8), 1-11. https://doi.org/10.3390/ijerph15081624

30. Lucas, R. M., Ponsonby, A. L., Dear, K., Valery, P. C., Taylor, B., van der Mei, I., McMichael, A. J., et al. (2013). Vitamin D status: Multifactorial contribution of environment, genes and other factors in healthy Australian adults across a latitude gradient. Journal of Steroid Biochemistry and Molecular Biolog, 136(1), 300-308. https://doi.org/10.1016/j.jsbmb.2013.01.011

31. Kift, R., Berry, J. L., Vail, A., Durkin, M. T., Rhodes, L. E., \& Webb, A. R. (2013). Lifestyle factors including less cutaneous sun exposure contribute to starkly lower vitamin D levels in U.K. South Asians compared with the white population. The British Journal of Dermatology, 169(6), 1272-1278. https://doi.org/10. 1111/bjd.12518
32. O'Sullivan, F., Raftery, T., van Weele, M., van Geffen, G. J., McNamara, D., O'Morain, C., Mahmud, N., et al. (2019). Sunshine is an important determinant of vitamin $d$ status even among high-dose supplement users: secondary analysis of a randomized controlled trial in Crohn's disease patients. Photochemistry and Photobiology, 95(4), 1060-1067. https://doi.org/10.1111/php. 13086

33. Andersen, R., Molgaard, C., Skovgaard, L. T., Brot, C., Cashman, K. D., Jakobsen, J., Lamberg-Allardt, C., et al. (2008). Pakistani immigrant children and adults in Denmark have severely low vitamin D status. Eurpean Journal of Clinical Nutrition, 62(5), 625-634. https://doi.org/10.1038/sj.ejcn.1602753

34. Eggemoen, A. R., Knutsen, K. V., Dalen, I., \& Jenum, A. K. (2013). Vitamin D status in recently arrived immigrants from Africa and Asia: A cross-sectional study from Norway of children, adolescents and adults. British Medical Journal Open, 3(10), 1-8. https://doi.org/10.1136/bmjopen-2013-003293

35. Brot, C., Vestergaard, P., Kolthoff, N., Gram, J., Hermann, A. P., \& Sorensen, O. H. (2001). Vitamin D status and its adequacy in healthy Danish perimenopausal women: Relationships to dietary intake, sun exposure and serum parathyroid hormone. British Journal of Nutrition, 86(Suppl), 197-103. https://doi.org/10.1079/ bjn2001345

36. Heerfordt, I. M. (2018). Sunscreen use at Danish beaches and how to improve coverage. Danish Medical Journal, 65(4), 1-13.

37. Idorn, L. W., Datta, P., Heydenreich, J., Philipsen, P. A., \& Wulf, H. C. (2013). Sun behaviour after cutaneous malignant melanoma: A study based on ultraviolet radiation measurements and sun diary data. British Journal of Dermatology, 168(2), 367-373. https:// doi.org/10.1111/bjd.12066

38. Wulf, H. C. (1986). Method and an apparatus for determining an individual's ability to stand exposure to ultraviolet radiation. America Patent and Trademark Office, US Patent no.4882598, $1-32$.

39. Kongshoj, B., Thorleifsson, A., \& Wulf, H. C. (2006). Pheomelanin and eumelanin in human skin determined by high-performance liquid chromatography and its relation to in vivo reflectance measurements. Photodermatology, Photoimmunology \& Photomedicine, 22(3), 141-147. https://doi.org/10.1111/j.1600-0781.2006. 00215.x

40. Wulf, H. C., Philipsen, P. A., \& Ravnbak, M. H. (2010). Minimal erythema dose and minimal melanogenesis dose relate better to objectively measured skin type than to Fitzpatricks skin type. Photodermatology, Photoimmunology \& Photomedicine, 26(6), 280-284. https://doi.org/10.1111/j.1600-0781.2010.00544.x

41. Baczynska, K., O’Hagan, J. B., Pearson, A. J., \& Eriksen, P. (2011). Temperature correction of UV spectral solar measurements for ICEPURE project. Photochemistry and Photobiology, 87(6), 1464-1467.

42. Mosteller, R. D. (1987). Simplified calculation of body-surface area. New England Journal of Medicine, 317(17), 1098-1098. https://doi.org/10.1056/NEJM198710223171717

43. Heerfordt, I. M., Philipsen, P. A., Larsen, B. Ø., \& Wulf, H. C. (2017). Long-term trend in sunscreen use among beachgoers in Denmark. Acta Dermato-Venereologica, 97(10), 1202-1205. https://doi.org/10.2340/00015555-2772

44. Young, A. R., Narbutt, J., Harrison, G. I., Lawrence, K. P., Bell, M., O'Connor, C., Olsen, P., et al. (2019). Optimal sunscreen use, during a sun holiday with a very high ultraviolet index, allows vitamin D synthesis without sunburn. The British journal of Dermatology, 24(5), 1052-1062. 31069787[pmid] PMC6899952[pmcid]. 